University of Washington Tacoma

UW Tacoma Digital Commons

Social Work \& Criminal Justice Publications

Social Work \& Criminal Justice

2017

\title{
A Retrospective Look at the Experience of Parental Incarceration and Family Reentry During Adolescence
}

Carrie Jefferson Smith

Diane S. Young

University of Washington Tacoma, youngd4@uw.edu

Follow this and additional works at: https://digitalcommons.tacoma.uw.edu/socialwork_pub

\section{Recommended Citation}

Smith, Carrie Jefferson and Young, Diane S., "A Retrospective Look at the Experience of Parental Incarceration and Family Reentry During Adolescence" (2017). Social Work \& Criminal Justice Publications. 482.

https://digitalcommons.tacoma.uw.edu/socialwork_pub/482 


\title{
A Retrospective Look at the Experience of Parental Incarceration and Family Reentry During Adolescence
}

Key words: Parental Incarceration; Adolescence; Mental Health; Health; Parent child relationship

\author{
Carrie Jefferson Smith, DSW (Corresponding Author) \\ Syracuse University \\ School of Social Work \\ 284 White Hall \\ Syracuse, NY 13244 \\ 315.443.5552 (office), 315.443.5576 (Fax) \\ cjsmith@syr.edu \\ Diane S. Young, Ph.D. \\ University of Washington - Tacoma \\ Social Work and Criminal Justice Program \\ 1900 Commerce St. \\ Box 358425 \\ Tacoma, WA 98402 \\ 253.692.4703 \\ youngd4@uw.edu
}

We would like to acknowledge the contributions of the young people who shared their experiences with us. Without them this work would not have been possible.

Financial support was provided by the University of Washington - Tacoma Social Work and Criminal Justice Program and the Syracuse University School of Social Work.

Carrie Jefferson Smith is an Associate Professor of Social Work and the immediate past Director of the School of Social Work at Syracuse University. She has conducted research on issues in child welfare, including grandparents raising children and parental incarceration. Her social work practice experience includes over 18 years in the public sector in child welfare and administration, emphasizing child abuse and neglect and permanency planning services.

Diane S. Young is the Director of the Social Work and Criminal Justice Program and Associate Professor of Social Work at the University of Washington Tacoma campus in Washington State. She has conducted research and published on social work practice within the justice system, jail mental health services, and families and children affected by parental incarceration. Her social work practice experience includes working within the criminal justice field for 10 years. 
A Retrospective Look at the Experience of Parental Incarceration and Family Reentry During Adolescence

\begin{abstract}
Few studies provide firsthand experiences of parental incarceration in adolescents' own voices. Fourteen young men and women retrospectively shared their experiences of parental incarceration and family reentry during adolescence. Individual interviews focused on the following qualitative research questions: 1) What is the experience of parental incarceration and reentry for adolescents? 2) How does the child-parent relationship change from pre- to postincarceration? Relationships with incarcerated parents tended toward estrangement, and negative emotions and need for emotional support were predominant in the sample. Findings have implications for improving mental health services for children and families, trauma work, and policy interventions across services.
\end{abstract}


A Retrospective Look at the Experience of Parental Incarceration and Family Reentry During Adolescence

Dramatic increases in incarceration rates in the United States and the number of inmates with children have exposed untold families to the often long-term and negative effects of incarceration and family reentry. The poor and certain racial and ethnic minority groups are disproportionately impacted. Adolescents face unique challenges with parental incarceration and family reentry, and through their own voices we may glean invaluable information to ensure their paths toward success.

The population of children with an incarcerated parent increased by $80 \%$ between 1991 and 2007 (Glaze \& Maruschak, 2008). The consequence was that an estimated 1.7 million children under age 18 , or $2.3 \%$ of the U. S. population, had an incarcerated parent at year-end 2007 (Glaze \& Maruschak), the last date that systematic national Bureau of Justice data were collected specifically on this population. Despite a recent downward trend in incarceration, by the end of 2015, approximately 1 in 37 adults in the U. S. were under some type of correctional supervision (Kaeble \& Glaze, 2016), and the number of incarcerated parents remains significant. Although there is no national data on the recidivism rate for parents who are incarcerated, it is estimated that within three years of release nearly $70 \%$ of former state prisoners are re-arrested for new crimes and 50\% are re-incarcerated (Durose, Cooper, \& Snyder, 2014). Thus, recidivism also exposes numerous families to multiple incarcerations and family reentries.

Communities of color and the poor are disproportionately impacted by incarceration. Wildeman and Wakefield (2014) suggest that incarceration has become commonplace for families who reside in the poorest communities, especially for their male members. African American men have a 1 in 3 likelihood of being incarcerated in their lifetime compared to 1 in 6 
for Hispanic men and 1 in 17 for white men (Bonczar, 2003). The result of this chilling disproportionality is that black children are 7.5 times more likely to have an incarcerated parent than white children (Glaze \& Maruschak, 2008).

An estimated 40\% of children of incarcerated parents are ages 10 to 17 (Mumola, 2000), while about $15 \%$ are ages 15 through 17 (Glaze \& Maruschak, 2008). Although children at different ages and circumstances likely experience parental incarceration and family reentry differentially, due to developmental processes, adolescence may make parental incarceration a particularly challenging period (Parke \& Clarke-Stewart, 2003). This is the time when young people still need the support and nurturing of parents and family, yet require the separation and developing independence that foster healthy relationship formation, educational attainment and skills for employment needed in adulthood. Attachment theory suggests that the separation of parents and children disrupts the parent-child bond and the developmental process (Sroufe, 1998). In addition, the incarceration of a parent often contributes to an already burdened environment characterized by poverty, stress and trauma (Travis \& Waul, 2003). Nonetheless, disruption of the family and the frequently felt trauma associated with incarceration and other aspects of arrest of a parent may hinder the child's current development. Also, these may create barriers to future child-parent relationship after parental release and family reentry.

Family reentry also may pose difficulties for parents and children. Most notably families and incarcerated parents may be poorly prepared for the reentry, and families may be financially strained and lack adequate housing. Previously incarcerated parents experience inadequate employment opportunities, continued alcohol or substance abuse problems, untreated health and mental health problems and difficulty re-establishing positive parenting and family relationships (Travis \& Waul, 2003). Adolescents are uniquely qualified to inform us about their experiences 
and to identify and share vulnerabilities and strengths that foster our understanding of needed strategies to facilitate their future success.

\section{Parental Incarceration and Child Wellbeing}

There have been numerous studies about parental incarceration in the last 20 years, yet gaps remain in our understanding about the impacts of parental incarceration on child wellbeing. Researchers acknowledge that the issues are confounded by the complexities of social and community environments, methodological challenges, and research that, for the most part, does not incorporate children's experiences from their own perspectives (Bendheim-Thoman Center for Research on Child Wellbeing, 2008; Johnson, 2006; Murray \& Farrington, 2008a; and Phillips, Erklani, Keeler, Costello, \& Angold, 2006). However, several studies have reported deleterious effects of parental incarceration on child and adolescent wellbeing. The risk to children's economic wellbeing (Glaze \& Maruschak, 2008; Western \& Petit, 2010) and concomitant housing insecurity (Casey, Shlafer, \& Masten, 2015; Desmond, 2012; Tasca, Rodriguez, \& Zatz, 2011; Wildeman, 2014), material hardship (Bendheim-Thoman Center for Research on Child Wellbeing, 2008; Geller \& Curtis, 2011) and use of public assistance (Bendheim-Thoman Center for Research on Child Wellbeing, 2008) are well documented. In turn, economic disadvantage powerfully impacts mental and physical health.

Children of incarcerated parents also experience an array of behaviors and issues that impact grade retention (Cho, 2009) and school performance (e.g., higher percentage of speech/language difficulties, attention deficit hyperactivity disorder and behavioral problems) (Morsy \& Rothstein, 2016). Geller, Garfinkel, Cooper, and Mincy (2009) documented increased aggressive behaviors among boys with incarcerated parents when the children were as young as age three. Also, children of incarcerated parents suffer from a variety of physical and social 
issues such as migraines, depression, anxiety, asthma, post-traumatic stress disorder, stigmatization and homelessness to a greater degree than those without incarcerated parents (Morsy \& Rothstein, 2016). The myriad challenges of children of incarcerated parents continue during adolescence and contribute to the unique concerns of older youth with incarcerated parents.

\section{Adolescents with Incarcerated Parents}

Adolescence is a unique developmental stage when youth are beginning to establish their independence, and exposure to parental incarceration and reentry may create vulnerabilities that threaten to derail a positive trajectory. For example, Cho (2010) suggests that the lack of supervision experienced by some adolescents with incarcerated parents may contribute to maladaptive behaviors and coping skills. Such maladaptive skills may link to increased aggression (Dallaire, 2007). Increased potential for delinquency has also been identified as a vulnerability for adolescents with incarcerated parents (Geller et al., 2009), and criminal behavior is one of the most frequently expressed concerns about this population, especially for boys (Aaron \& Dallaire, 2010; Huebner \& Gustafson, 2007; Murray \& Farrington, 2005). Also, adolescents who experience parental incarceration are at greater risk of school dropout than youth without incarcerated parents. For example, in a large study of incarcerated mothers, Cho (2011) found that children whose mothers are incarcerated in the child's early adolescence (1114 years) or late adolescence (15-17 years) were significantly more likely to drop out than all other children. Cho (2011) also found that boys were more likely to drop out than girls, in part due to their own incarceration.

The trauma of experiencing parental incarceration, in and of itself, may be an area of vulnerability for adolescents. Trauma may be deepened by conditions of poverty or chaotic 
community environments (Dannerbeck, 2005; Sampson \& Loeffler, 2010). Trauma manifests in a variety of internalized emotions such as sorrow, worry, guilt, and fear (Zahn-Waxler, KlimesDougan, \& Slattery, 2000). Additionally, trauma may be expressed in externalizing problems, such as anti-social behavior, delinquency, substance abuse, and violence, all of which have the potential to contribute to social, health, and mental health problems that persist throughout adolescence and beyond. Boss (2010) has applied the concept of "ambiguous loss" to traumatic events that represent "a unique kind of loss that complicates grief, confuses relationships, and prevents closure" (p. 137). The example of someone who experiences drug addiction most clearly demonstrates an ambiguous loss. It is often difficult to grieve or manage the stress because there is uncertainty about the situation. When addiction is present, the addicted person may be physically present but emotionally unavailable because of preoccupation with sustaining access to the drug of choice. In the case of incarceration and reentry, the trauma of having a parent "suddenly just gone" as one of our participants stated, or "not being the same parent" when they return as another said, may be experienced as ambiguous loss. This sense of loss may in turn contribute to the kinds of problems that are prevalent among adolescents with incarcerated parents such as anxiety, depression, bedwetting, sleep disturbances, attention difficulties, physical aggression, and family conflict (Morsy \& Rothstein, 2016; Murray \& Farrington, 2008b; Wildeman, 2010).

\section{Family Reentry}

Most incarcerated persons are eventually released and return to their families and communities. Reentry involves many challenges. Among the most important aspects of reentry is finding gainful employment that enables the formerly incarcerated parent to support him or herself and contribute to the support of one's children. Employment is often difficult to acquire 
with a criminal record. A history of incarceration has been found to decrease the average earning potential by $40 \%$ annually (Western \& Petit, 2010). Lack of employment may contribute to family tensions. In addition, a felony conviction may limit available housing options, thwarting opportunities for stability and putting the person at risk of homelessness (Travis \& Waul, 2003). In a study of 49 returning prisoners from New York prisons and jails, the two most needed resources were an immediate place to stay and emotional support (Nelson, Deess, \& Allen, 1999).

Parents in state prisons serve on average a maximum sentence of 12 years (Travis \& Waul, 2003). Long sentences and the inability to maintain family contact during incarceration create complications in family dynamics that can disrupt and erode relationships, including the parenting relationship and lines of authority between parents and children (Hairston, 2003). Furthermore, a loss of trust between parent and child resulting from parental criminal behavior and incarceration can linger and may intensify and further erode relationships if the parent recidivates. Returning parents may also suffer from untreated physical and mental health problems (Rose \& Clear, 2003). All the aforementioned issues complicate reentry and adjustment following parental incarceration.

Parental incarceration and family reentry have emerged as important and complex issues related to the wellbeing of children. Adolescents face unique challenges and are well positioned to better inform us about their lived realities.

\section{Methods}

\section{Sampling Procedure}

Fourteen young adults, ages 18 through 28 , consented to share their experiences related to parental incarceration and reentry during the time of adolescence. They responded to one of 
several requests that went out with information about the study via emails, listservs, social media and posted fliers. Notices were sent via social work student listservs at two universities, the criminal justice student listserv at one university and were posted on social media sites (i.e., Facebook, Twitter) managed by the two universities' social work departments. The authors also contacted community agencies and asked them to post the flier or share information about the study with appropriate clients. Two community agencies working with persons involved in criminal justice systems, one in the Northwest and one in the Midwest regions of the United States, offered to help with participant recruitment and did so through word of mouth and posting a flier. Two individuals were known to the authors as young adults who had disclosed histories of parental incarceration and consented to be participants. This recruitment strategy resulted in participants from four different states at the time of the interviews: Pennsylvania, New York, Missouri, and Washington.

Prospective participants were screened for eligibility based on the following three criteria: 1) be age 18 through 29 years old, 2) have a parent incarcerated for at least 3 months when the participant was 12 through 17 years old, and 3) the incarcerated parent was significantly involved in the adolescent's life prior to parental incarceration. Participants selfdisclosed their age, estimated the length of parental incarceration during their adolescence based on memory, and decided for themselves whether their parent had been "significantly involved." A \$25 gift card was provided to participants as compensation for their time and any transportation-related expenses associated with participation. The study was approved by the Institutional Review Boards of the authors' universities.

\section{Sample Characteristics}


Table 1 provides basic information about the sample. Participants were asked to describe in greatest detail the parental incarceration that was most significant to them; for this study, this was considered the primary incarceration. For 7 participants, the primary parental incarceration began prior to adolescence, defined as 12-17 years of age, and either extended through adolescence or was followed by a subsequent incarceration that overlapped the adolescent years. Only two of the incarcerated parents did not live with their children prior to their incarceration. Participants reported their parents were incarcerated for crimes involving drugs, fraud, arson, child molestation, and murder. They were incarcerated from 6 months to life, with 10 of the parents serving more than 2 years in prison. Six of the parents were incarcerated once; 3 were incarcerated twice; 5 were incarcerated 3 or more times. Three parents had not been released since the primary incarceration and up to the point of participant interviews. Two of these parents will likely not be released during their lifetimes based on the length of their sentences.

\section{Study Design}

The study used mixed methods and included retrospective questions, asking participants to reflect on their childhood and adolescence, and questions about their current lives as young adults. After giving informed consent, participants first completed a survey with primarily closed-ended questions related to demographic characteristics about themselves and their incarcerated parent, age/s at time of parental incarceration and reentry, length of parental incarceration/s, and how involved the parent was in their life before, during and after each incarceration. Face-to-face or telephone interviews were then conducted with each participant by one of the authors or a graduate social work student who was trained in conducting research interviews. The interviews were semi-structured, consisting of pre-developed, open-ended questions, but allowing room for modification and deeper exploration when relevant. The 
interview guide was organized into sections with questions pertaining to the participant's life at different stages of parental incarceration and reentry, from a point prior to the first parental incarceration the participant could remember to current life as a young adult. Participants were encouraged to share their experiences and perceptions of them. Interviews ranged from 50-154 minutes, with a mean of 75 minutes.

\section{Data Analysis}

Qualitative analysis is especially helpful when the perspectives of participants as insiders are sought on a topic and it is important to understand the contexts that shape those perspectives (Padgett, 2008). Understanding the experiences of parental incarceration and reentry as viewed through the perspectives of the children who had these experiences would not easily be captured through solely quantitative measurement. All interviews were conducted, taped and transcribed prior to analysis. Given the preliminary nature of the exploration and the small sample size, description rather than theory building shaped the analysis approach. All qualitative data were analyzed manually. Using an analysis process described by Tutty, Rothery, and Grinnell (1996), the unit of analysis is the "idea." The authors divided the questions in the interview guide in half and then reviewed the transcripts in their entirety for comments related to each question in their half of the interview guide. All relevant comments for each interview guide question were placed in Word documents. Throughout this process, the authors consulted with each other if there was uncertainty about where to place a comment. Because the transcripts in their entirety were reviewed, not just the section of the interview that directly asked each question, the result was a more complete array of responses for the second level of analysis. For example, it was not unusual for participants to discuss how an experience now is tied to experiences during childhood, even when the focus of the question was elsewhere. 
During the second stage of analysis, both authors read through each Word file, containing the comments relevant to a particular question, in order to identify key ideas and meanings to be learned about the participants' experiences. From this discussion emerged the outlines for two manuscripts, one focused on the participants' experiences of parental incarceration and reentry as adolescents and one on the participants' experiences as young adults and the ways these experiences continue to impact them. The authors then again sorted the Word files into two sets according to which manuscript they more closely aligned with for the third and final analysis stage. Each author took one set of files and conducted a fine-tuned analysis of the themes and sub-themes relevant to each interview question, identifying similarities and differences across participants' experiences. Findings for each interview question were summarized and written up and included identified themes and sub-themes. These written summaries were then reviewed by the other author, along with a review of each relevant Word file, to determine whether the conclusions drawn "rang true" to the narratives. The few areas of disagreement were discussed and reconciled by re-reviewing the original transcripts.

To strengthen the trustworthiness of the analysis process and findings presented, strategies to enhance the rigor of the study were employed. These included a concerted effort to pay attention to the wide variation of participants' experiences expressed in the narratives, a careful recording of process decisions throughout, and continuous checking in and doublechecking of each other's analysis process and conclusions.

This manuscript focuses on the perspectives and experiences of the participants during adolescence. We address the following broad research questions: 1) What is the experience of parental incarceration and family reentry for adolescents? 2) How does the relationship with the parent change from pre- to post-incarceration? 


\section{Findings}

The participants discussed the experiences and changes that took place in their lives when their parents were incarcerated, re-entered family life after incarceration, and during subsequent incarcerations. Changes occurred in three domains: 1) personal impacts, such as emotional and behavioral changes, 2) within home and family, and 3) in the broader environment, predominantly school and community. All participants described impacts in the personal and home and family domains and some also described impacts in the school and community domain.

\section{Experience of Parental Incarceration}

Personal. Participants identified a range of emotions that they experienced following parental incarceration. These included anger, resentment, sadness, grief, anxiety, fear, guilt, confusion, feeling overwhelmed or out of control, not feeling normal, concern for their parents' victims, loss of hope, and feeling neglected, unloved or abandoned. Several participants acutely felt a sense of loss or "not having." Part of this "not having" was the loss of what could have been and missing out on what they perceived other young people without incarcerated parents had. One participant expressed that belief this way: "As an adolescent, the hardest thing was kind of dealing with the image...I wanted to have that all American [life]." Except for the few participants whose lives were better during parental incarceration, the majority of participants missed their incarcerated parent. The loss of the parent's physical presence, daily interaction, affection, and financial and caregiving contributions caused their sense of loss and the feeling that they were missing out on something. One participant described this loss as the "vanishing" of a parent. Two female participants talked about how awkward it was for them not to have the presence and emotional support of their incarcerated mothers when they experienced the 
developmental milestone of starting their menstrual cycle. Moreover, not feeling sure about what was going on created a sense of unease for some participants. One wondered, "Did I have anything to do with what's happening?" These feelings touched and shaped all domains of their adolescent lives.

Other areas of personal impact following parental incarceration involved behavioral and physical responses including self-isolation or withdrawal, overeating and weight gain, and selfharm behavior (cutting) or suicidal ideation. Two participants needed medication to manage physical symptoms caused by stress. Three participants responded to the influences of stressful and negative environments and the experience of "not having" by stealing or drug use and/or sales. Three also became parents while still minors.

Home and Family. Instability and a reduction in economic status were experienced by most participants. Ten reported that physical moves were one of the more significant changes in their living situations during their parents' incarcerations. More than half (8) reported having to move 2 or more times, and 1 participant reported a period of living in a homeless shelter, while another created her own informal foster care arrangement. Five participants described moves that resulted in families taking up residence in neighborhoods that they viewed as less safe than the previous ones they lived in.

Participants also reported changed responsibilities in the home once their parent was incarcerated. Two thirds of the participants stated that their responsibilities increased. This included taking on parenting responsibilities for siblings, doing more household chores, going to work to help financially, and engaging in truly adult responsibilities such as talking to bill collectors and providing emotional support for the remaining parent. Additionally, one described 
having to pick up the responsibilities of the incarcerated parent to support the remaining parent who had a disability.

Other significant adjustments were required due to changing family composition. Three participants had an adult relative or friend move into the home to assist the family with child care or other needs. One participant who had to move in with relatives described "always a feeling of not being at ease in someone else's house when you're staying there kind of uninvited." Relationships also changed because of increased work demands or pursuit of education by the remaining parent or grown siblings. For some participants, family members were split up as siblings left or were removed for various reasons. New alliances were formed and disciplinary roles shifted, further stressing family relationships. For at least two participants, the changes resulted in an easing of tension and reduced family conflict, allowing the adolescent to feel more at peace, because the incarcerated parent had been the cause of chronic family discord.

School and Community. Although school was described as a stabilizing force for several participants, at least half reported difficulties at school after parental incarceration. These involved performance and behavior problems ranging from telling lies to fighting that resulted in suspension. The loss of friends and peers because of frequent school moves was a common theme. One participant moved so often that she attended five different high schools. Making new friends was not easy, partly because of concerns with sharing information about the incarcerated parent. At least five participants perceived some level of embarrassment or stigmatization from their peers or teachers at school or within the neighborhood because of parental incarceration. One participant reported being bullied at school.

\section{Experience of Family Reentry After Incarceration}


The lives of the seven participants who experienced a family reentry during adolescence did not change or improve markedly following parental release from prison or jail. This was true in all three domains: personal, home and family, and school and community. With rare exceptions, difficult circumstances remained. Family financial situations remained depressed when the parent returned. In two cases, they deteriorated further. For example, one participant's family went on welfare and had to move into public housing and another's father purchased a house, but later went into bankruptcy. Most often, family members' roles did not revert to those that existed prior to incarceration. For example, one participant no longer viewed his father as an authority figure and continued to rely on his own resources to survive, selling drugs to get by. In another situation, the parental role had been permanently assumed by informal foster parents, and the participant's father could not convince her to live with him after his release. Also, several returning parents remained under correctional mandates after release. This was perceived to negatively impact the relationship between parent and child, infringing on the time that parents could engage in relationship maintenance with participants by limiting their geographic mobility. The students who experienced school as a stabilizing force continued to do so, and those who had difficulty at school persisted in that vein as well.

On the other hand, most participants expressed some positive aspects related to parental return. The physical presence of the returning parent was noted as one of the things that participants most enjoyed, and was mentioned by almost all of them. Three participants reported that food was an important aspect of their relationship with their parents when they were released from incarceration. This appeared to be an important feature of physical nurturing and likely also was experienced emotionally as an act of caring. The returned opportunity for communication and affection was also acknowledged by one participant. A sense of a return to a 
more "normal" or stable existence or a happier time was noted by three participants. For one participant, this meant she could reclaim relationships with friends and become a teenager again after her mother's release. A small number also commented on the relief they felt at seeing their parent working and seeing improvements in their parent's behavior and circumstances.

Intermingled with the positive statements, however, were expressed fears that things might get worse again. Indeed, two participants reported experiencing nothing positive about their parents' return from incarceration.

\section{Experience of Parental Re-incarceration}

Five participants experienced re-incarceration of a parent during adolescence or shortly thereafter, up to the age of 19. This came with an array of negative emotions, including sadness, anger, resentment, and hurt. One participant described the anger he felt toward his father when he was re-incarcerated. Believing his father had lied to him, he lost faith in him. One female participant described the emotional progression she experienced from deep sadness at the initial incarceration, to sadness at the second incarceration, to anger and hurt the third time her father was incarcerated. Another participant described her father's multiple incarcerations as “a repeated cycle that kept going." Multiple incarcerations left participants feeling as though they did not have control over their lives. In part, this was because they felt naïve about how decisions are actually made in the legal system. In some cases, participants believed the criminal justice response too harsh. For example, one participant stated her father had just found a decent job and was generally doing well when he was returned to prison. Another saw the police "manhandle" his father and trash the house at the time of re-arrest. These experiences compounded participants' frustration and confusion. Mixed with the emotional aspects of the re-incarceration were very real concerns about the financial status of the family and the need to fully resume 
adult responsibilities. One participant who had been able to relinquish responsibility for her younger sibling with her father's release now experienced anger and concern that she had to inform her sister about the re-incarceration and ensure that she had a place to stay. Finally, for a couple participants, risk-taking and illegal behavior, such as drug use and sales, increased with parental re-incarceration. Thus, feelings of anger and loss generally escalated with the increase in number of parental incarcerations along with getting into trouble themselves for some.

Along with the experience of negative emotions, several participants found ways to cope with parental re-incarceration. This was easiest when it did not disrupt their regular routines and stability. For example, one participant found the re-incarceration of her father easier because she was established in an informal foster care situation that she had found for herself. Her living situation was thus unchanged when her father went back to jail. One participant found that regular contact with his father made his father's absence more bearable. Another coping strategy, mentioned by only two participants, was simply accepting parental incarceration as an established pattern in their lives, one that was about the parent and not about them or who they were. One participant, who experienced multiple parental incarcerations, firmly believed that people should face the consequences of their behavior and this helped her adjust to repeat parental incarcerations. Interestingly, as a teenager, another participant experienced her father's return to incarceration as a break from his oversight. She stated,

There would be sometimes when he would get on my nerves, like he'd be harassing me about homework or staying on task or being where I was supposed to be. I can remember thinking, 'Oh, he'll go to jail soon and leave me alone.

Later she would miss him, but she initially enjoyed his absences.

For the four participants who experienced yet another family reentry after a second parental incarceration during adolescence and prior to age 18, their living situations moved along 
the same, typically negative, trajectory that had been set in motion by the first incarceration. Anger was a predominant emotion. One male participant stated that he became increasingly aware that his situation was dire. He experienced despair over feeling trapped in the same environment that created his father's circumstances and felt a deep sense of unfairness. The female participant living with informal foster parents maintained her anger toward her father and became emotionally closer to her informal foster parents.

\section{Relationship with Parent}

Participants were asked to talk about what their relationship with their incarcerated parent was like and how it changed at various stages: pre-incarceration, during incarceration, after release, and during subsequent incarcerations and releases if applicable. Table 1 provides the range of ages of participants at the time of primary parental incarceration and release. Based on the participants' comments and indicators of connection with the parent, we assigned a numerical rating ranging from " 1 " to " 4 " to depict the closeness of the relationship between the child and parent at different stages of parental incarceration during their adolescence. On the scale a " 1 " represents a very negative or poor relationship and "4" a very positive or good relationship. Relationships rated a " 4 " had positive and mutually reciprocated contact between parent and child. More positive than negative relationships (rated "3") had ongoing communication with minimal resistance to interactions between the participant and the incarcerated parent. More negative than positive relationships (rated "2") included strained communication and moderate resistance by the child to contact with the incarcerated parent. Relationships rated a " 1 " evidenced inconsistent communication and/or strong resistance or avoidance on the part of the child to communicate with or visit the incarcerated parent. Table 2 provides the relationship ratings at various stages of incarceration. With the experience of parental incarceration, most 
child-parent relationships shifted from the positive end of the scale to the negative and remained there.

Prior to Incarceration. Most participants (10) verbally indicated a positive relationship with their parent prior to incarceration. They describe memories of attentive caretakers (permanent and intermittent) who offered emotional support and continuity. Because of the young ages of some of the participants at the time of the parent's primary incarceration however, in some cases there is not much information on which to base the rating. One participant, given a rating of " 3 ," reported a strong pre-incarceration relationship with her father and also expressed frustration because he was using drugs and often had his drug-using friends over to the house, which caused her distress. Two participants, rated as "1" on the relationship scale, described negative memories of parental alcohol and drug use, spousal and child abuse, and neglect.

During Incarceration. Most often relationships with incarcerated parents moved in a less-engaged and more negative direction when compared to the time prior to incarceration (see Table 2). The only means for the adolescents to maintain contact with their incarcerated parents were through visiting, letters, and phone calls. Five of the 14 participants were able to visit their parents in prison or jail, although visiting was very infrequent for all 5. One participant described the tremendous difficulty visiting her father entailed:

My dad was 7-8 hours away driving, and we only saw him once a year because it would take [time] for us to plan, save money so that we could go there during the day, so that my mom could take off work, or my brother could take off work. We would book a hotel room. It was in the middle of nowhere.

For other participants, visiting was not feasible or appropriate. One participant's father was moved to prisons far from the state where she lived. In another case where the father was in prison for sexual abuse, the participant's mother was advised not to bring the participant to visit him anymore. 
Of the remaining 9 participants who did not visit their incarcerated parents, 2 had no contact with their parents and 7 received letters and/or calls. Letters and calls were sporadic for most. Typically contacts between the youth and their incarcerated parents were strained. Even in situations where contacts between the participant and parent started off on an optimistic note ("it started off being really exciting getting a letter from him because I felt, really, still connected to him"), as the period of incarceration continued, the relationship became thwarted by ambivalence and negativity. One participant explained:

He would write me letters and I would read them and the first few they would get me all choked up but then as they went on, I don't even know the word, I just didn't wanna talk to him anymore.

Another stated:

We were able to talk on the phone, but I don't really recall enjoying talking to him - we didn't have anything to say to each other really. My dad just didn't know who I was and what my interests were, and so all we could talk about was him being in jail, and he was sorry.

One custodial parent enabled deception on the part of the youth to allow her the option of not communicating with her incarcerated father. She stated: "He would write a lot. And he would call too, but I would never answer; my mom wouldn't tell him I was home.” Even relationships that had previously been quite positive became decidedly more negative throughout the period of parental incarceration as children and parents lost connection and common experiences with each other. For participants who experienced multiple parental incarcerations, contacts became even more infrequent with subsequent incarcerations. No visits occurred and there were fewer calls and letters. For these participants, the child-parent relationships moved from "more negative than positive" to "very negative" on the relationship scale. In contrast to these more negative accounts, one participant reported maintaining a very close connection to her incarcerated 
mother. She stated, "We wrote each other letters - she wrote us letters every week of every month. I still have my letters to this day that she wrote me."

Post-Incarceration and Family Reentry. Not all participants experienced parental reentry to the home. In two cases, the offending parent was released following the participant's $18^{\text {th }}$ birthday and they were living elsewhere as independent adults. In three cases, the parent had not yet been released by the time of the study interview. These 5 participants were not given a relationship rating at this stage.

The post-incarceration relationship between participants and their parents varied from close with regular contact to non-existent with no contact. The majority of relationships were negative (see Table 2). Only one participant noted that the relationship became "closer" following the return of her mother. This was attributed to constant letter exchanges between them. More often participants began to view their parents differently as their understandings of their parent's criminal and destructive behaviors matured and as the realization dawned that things would not return to a better time. Some expressed anger or resentment toward the formerly incarcerated parent. Issues of hurt and lost trust were evident. One male participant stated:

The heartbreak. I didn't even want to call him my daddy. I'm just like, I didn't even hang with him like my older brother hung with him at the time. I'm like, 'You can't show me nothing.' I just didn't feel like nothing for him in my heart.

Another participant expressed the change in relationship with her father this way:

I just couldn't talk to him the way I once talked to him and couldn't hang out with him the way we did hang out before. When he got out of jail to talk to me and be a dad...I wouldn't let him. So that's kinda what I learned to do, it was just push him away.

One participant also described feeling burdened because her previously incarcerated father often said he would kill himself if he lost the love of his children. She felt obligated to stay connected 
and to demonstrate she cared for him whether she wanted to or not. In one of the most extreme examples of negative child-parent relationship, one male participant, seriously abused and neglected by his mother prior to her incarceration, found things once again very difficult when she returned home. He described walking the streets all night with nowhere to stay when his mother kicked him out of his grandmother's home where she was also staying.

\section{Discussion}

This study explores the experience of parental incarceration and family reentry during adolescence through the voices of young people who experienced it. The participants in the study reflect on their relationships with the incarcerated parent before, during and after incarceration and family reentry. Most of the participants in this study reported experiencing a close relationship with parents prior to incarceration. However, the adolescent-parent relationships changed from pre- to post-incarceration, reflecting a general trend over time toward estrangement and contributing to increased stress. This was especially true in situations where there were multiple incarcerations.

As in other research on the impact of parental incarceration, the long-term impacts of poverty and other social, health, and economic forces were difficult to disentangle from factors related to the adolescents' experiences of parental incarceration. It was evident that the economic wellbeing of all the participants in this study took a negative trajectory following their parents' incarceration. In addition, parental reentry into the lives of the adolescents did not improve their economic life circumstances. Also, similar to findings from other studies on the subject, the experience of parental incarceration seems to have powerfully shaped the adolescents' emotional and psychological responses, health, and coping strategies that took a toll on them during their adolescent years and beyond. 


\section{Limitations}

One of the most challenging methodological aspects of doing this study was recruitment. We recruited widely using various techniques over an extended period, and 14 individuals chose to participate. Some of the participants spoke about how difficult it was to talk about the subject, indirectly offering a possible explanation for the challenge in recruiting. Despite the small number of participants, there is growing evidence that sample sizes as small as 6 individuals in qualitative studies are sufficient for adequately surfacing the majority of themes found in larger samples (Guest, Bunce, \& Johnson, 2006; Hennink, Kaiser, \& Marconi, 2016), providing confidence that a robust array of relevant themes are present among our sample. An additional methodological challenge was that for the interview questions that are the foci of these analyses, participants had to rely on their ability to recall details and experiences that happened some years ago, when they were children. The memories and perspectives are those they hold in the present as they reflect on earlier times; if they had been interviewed as adolescents, their perspectives and recall of details may have been different. Nonetheless, self-report data have been acknowledged as an essential tool in social science research, in part because the individual is the only one who can provide self-interpretations of events (Garcia \& Gustavson, 1997). Future research might address these limitations by finding additional access points to children of different developmental stages who are experiencing parental incarceration.

\section{Practice and Policy Implications}

The participants in this study experienced the loss and trauma that are associated with parental incarceration in multiple domains while adolescents. Some of what they describe might best be labeled ambiguous loss (Boss, 2010) as their situations demonstrate a complicated grief process that was thwarted by confused relationships with their incarcerated parents and an 
inability to establish appropriate closure. The loss experienced by participants was exasperated by lack of information, complications in communication and visitation, perceived stigmatization, psychological difficulties, social and economic instability, and health problems (including overeating, self-harm, and illegal drug use). Consistent with other research, the young people in this study reported that things did not improve greatly when previously incarcerated parents reentered the family (Bendheim-Thoman Center for Research on Child Wellbeing, 2008).

Participants expressed that they could have benefited from supports, services and programs. Their suggestions might be useful to policy makers and service providers seeking to assist youth who are going through similar situations of parental incarceration. Several young people suggested that they could have benefited from the support of an adult who served as a mentor and could offer opportunities to get out of the stress-filled home environment temporarily. Since some reported having to change schools due to a decline in economic circumstances or expressed feelings of anger, stigmatization, and secrecy at school regarding parental incarceration, school social workers and counselors skilled in trauma treatment and handling grief and loss issues could be beneficial. Correspondingly, programs within schools that help students manage the problems and emotions of children with incarcerated parents, like the Banana Splits school-based groups program for students who have experienced parental divorce or death (see the Banana Splits Resource Page at http://www.bananasplitsresourcecenter.org/) might be offered.

In addition to the suggestions offered by participants, community level interventions that reduce barriers to establishing normalcy for the released parent are necessary. Specifically, programs to facilitate employment and treatment for addiction and mental health concerns are required if formerly incarcerated parents are to be able to realistically rebuild their lives after 
incarceration. The literature suggests that such support for the formally incarcerated is important in reducing recidivism as well (Rose \& Clear, 2003). Also, public information about the impact of incarceration is limited, and ways of informing the public and garnering support for the families who are left behind is an important strategy in shifting stereotypes and reducing stigma for children. For example, the Annie E. Casey Foundation (AECF) works to promote public awareness of important issues that impact children and families. AECF's (2016) recently created resource, A shared sentence: The devastating toll of parental incarceration on kids, families and communities, is a model for information needed to inform the general population about the realities for children, families and communities in the context of incarceration.

Few studies illuminate the conversation about parental incarceration by including the perspectives of adolescents who have experienced parental incarceration and family reentry firsthand. Including them sheds light on the unique concerns of this vulnerable population and appropriate preventions and interventions in response to the need for more effective and socially just approaches that address the impacts of parental incarceration on adolescents. 
Table 1. Sample Characteristics

\begin{tabular}{|c|c|}
\hline Characteristic & $\begin{array}{l}\text { Participants } \\
(\mathrm{N}=14)\end{array}$ \\
\hline \multicolumn{2}{|l|}{$\begin{array}{l}\text { Age at Primary Parental } \\
\text { Incarceration* }\end{array}$} \\
\hline 2 years & 1 \\
\hline 6-8 years & 3 \\
\hline $9-10$ years & 2 \\
\hline 11-12 years & 4 \\
\hline 16-17 years & 4 \\
\hline \multicolumn{2}{|l|}{$\begin{array}{l}\text { Age at Parental Release after } \\
\text { Primary Incarceration* }\end{array}$} \\
\hline $10-12$ years & 3 \\
\hline 13-15 years & 2 \\
\hline 17-19 years & 4 \\
\hline 20-22 years & 2 \\
\hline No release & 3 \\
\hline \multicolumn{2}{|l|}{ Age at Interview } \\
\hline 18 & 1 \\
\hline 19 & 1 \\
\hline 22 & 5 \\
\hline 24 & 3 \\
\hline 25 & 1 \\
\hline 27 & 1 \\
\hline 28 & 2 \\
\hline \multicolumn{2}{|l|}{ Gender } \\
\hline Female & 10 \\
\hline Male & 4 \\
\hline \multicolumn{2}{|l|}{ Race/Ethnicity } \\
\hline African-American & 6 \\
\hline Caucasian & 6 \\
\hline Hispanic & 2 \\
\hline \multicolumn{2}{|l|}{ Incarcerated Parent } \\
\hline Biological Father & 9 \\
\hline Stepparent Father & 2 \\
\hline Biological Mother & 3 \\
\hline
\end{tabular}

*For this study, the primary incarceration was the parental incarceration that the participant identified as most significant to him/her. It was not necessarily the parent's first incarceration. 
Table 2. Relationship Scale: Pre- to Post-Incarceration

\begin{tabular}{|l|c|c|c|}
\hline $\begin{array}{c}\text { Relationship } \\
\text { Rating }\end{array}$ & $\begin{array}{c}\text { Prior to } \\
\text { Incarceration }\end{array}$ & $\begin{array}{c}\text { During } \\
\text { Incarceration }\end{array}$ & $\begin{array}{c}\text { Post- } \\
\text { Incarceration/Family } \\
\text { Reentry }\end{array}$ \\
\hline $\begin{array}{l}\text { 1=Very } \\
\text { Negative }\end{array}$ & 2 & 2 & 3 \\
\hline $\begin{array}{l}\text { 2=More } \\
\text { Negative than } \\
\text { Positive }\end{array}$ & 2 & 11 & 3 \\
\hline $\begin{array}{l}\text { 3=More } \\
\text { Positive than } \\
\text { Negative }\end{array}$ & 3 & 0 & 0 \\
\hline $\begin{array}{l}\text { 4=Very } \\
\text { Positive }\end{array}$ & 7 & 1 & 1 \\
\hline Total N & 14 & 14 & 7 \\
\hline
\end{tabular}




\section{References}

Aaron, L., \& Dallaire, D. H. (2010). Parental incarceration and multiple risk experiences: Effects on family dynamics and children's delinquency. Journal of Youth and Adolescence, 39(12), 1471-1484. doi:10.1007/s10964-009-9458-0

Annie E. Casey Foundation. (2016, April). A shared sentence: The devastating toll of parental incarceration on kids, families and communities (Kids Count Policy Report). Retrieved from http://www.aecf.org

Bendheim-Thoman Center for Research on Child Wellbeing. (2008, April). Parental incarceration and child wellbeing in fragile families (Fragile Families Research Brief No. 42). Princeton University: Author. Retrieved from http://fragilefamilies.princeton.edu/sites/fragilefamilies/files/researchbrief42.pdf

Bonczar, T. P. (2003). The prevalence of imprisonment in the U.S. population, 1974-2001. Washington, DC: U.S. Department of Justice. Retrieved from http://www.cbsnews.com/htdocs/pdf/prisontime.pdf

Boss, P. (2010). The trauma and complicated grief of ambiguous loss. Pastoral Psychology, 59(2), 137-145. doi:10.1007/s11089-009-0264-0

Casey, E. C., Shlafer, R. J. \& Masten, A. S. (2015). Parental incarceration as a risk factor for children in homeless families. Family Relations, 64(4), 490-504. doi:10.1111/fare.12155

Cho, R. M. (2009). Impact of maternal imprisonment on children's probability of grade retention. Journal of Urban Economics, 65(1), 11-23. https://doi.org/10.1016/j.jue.2008.09.004

Cho, R. M. (2010). Maternal incarceration and children's adolescent outcomes: Timing and dosage. Social Service Review, 84(2), 257-282. https://doi.org/10.1086/653456 
Cho, R. (2011). Understanding the mechanism behind maternal imprisonment and adolescent school dropout. Family Relations, 60(3), 272-289. doi:10.1111/j.1741-3729.2011.00649.x

Dallaire, D. H. (2007). Incarcerated mothers and fathers: A comparison of risk for children and families. Family Relations, 56(5), 440-453. doi: 10.1111/j.1741-3729.2007.00472.x

Dannerbeck, A. M. (2005). Differences in parenting attributes, experiences, and behaviors of delinquent youth with and without parental history of incarceration. Youth Violence and Juvenile Justice, 3(3), 199-213. doi:10.1177/1541204005276260

Desmond, M. (2012). Eviction and the reproduction of urban poverty. American Journal of Sociology, 118(1), 88-133. doi:https://doi.org/10.1086/666082

Durose, M. R., Cooper, A. D., \& Snyder, H. N. (2014, April). Recidivism of prisoners released in 30 states in 2005: Patterns from 2005 to 2010 (NCJ 244205). Washington, DC: U.S. Department of Justice.

Garcia, J., \& Gustavson, A. R. (1997, January). The science of self-report. Observer, 10(1). Retrieved from https://www.psychologicalscience.org/observer/the-science-of-selfreport\#.WUgyHYWcGM8

Geller, A., \& Curtis, M. A. (2011). A sort of homecoming: Incarceration and the housing security of urban men. Social Science Research, 40(4), 1196-1213. https://doi.org/10.1016/j.ssresearch.2011.03.008

Geller, A., Garfinkel, I., Cooper, C. E., \& Mincy, R. B. (2009). Parental incarceration and child well-being: Implications for urban families. Social Science Quarterly, 90(5), 1186-1202. doi:10.1111/j.1540-6237.2009.00653.x

Glaze, L., \& Maruschak, L. (2008, revised 2010, March). Parents in prison and their minor children (NCJ 222984). Washington, DC: Bureau of Justice Statistics. 
Guest, G., Bunce, A., \& Johnson, L. (2006). How many interviews are enough? An experiment with data saturation and variability. Field Methods, 18(1), 59-82. doi: $10.1177 / 1525822 X 05279903$

Hairston, C. F. (2003). Prisoners and their families: Parenting issues during incarceration. In J. Travis \& M. Waul (Eds.), Prisoners once removed (pp. 259-282). Washington, DC: Urban Institute.

Hennink, M. M., Kaiser, B. N., \& Marconi, V. C. (2016). Code saturation versus meaning saturation: How many interviews are enough? Qualitative Health Research, 27(4), 591608. doi:10.1177/1049732316665344

Huebner, B. M., \& Gustafson, R. (2007). The effect of maternal incarceration on adult offspring involvement in the criminal justice system. Journal of Criminal Justice, 35(3), 283-296. https://doi.org/10.1016/j.jcrimjus.2007.03.005

Johnson, D. (2006). The wrong road: Efforts to understand the effects of parental crime and incarceration. Criminology \& Public Policy, 5(4), 703-719. doi:10.1111/j.1745-9133.2006.00414.x

Kaeble, D., \& Glaze, L. E. (2016, December). Correctional Populations in the United States, 2015 (NCJ 250374). Washington, DC: Bureau of Justice Statistics.

Morsy, L., \& Rothstein, R. (2016). Mass incarceration and children's outcomes: Criminal justice policy is education policy. Washington, DC: Economic Policy Institute. Retrieved from www.epi.org

Mumola, C. J. (2000). Incarcerated parents and their children (NCJ 182335). Washington, DC: Bureau of Justice Statistics. 
Murray, J., \& Farrington, D. P. (2005). Parental imprisonment: Effects on boys' antisocial behavior and delinquency through the life-course. Journal of Child Psychology and Psychiatry, 46(12), 1269-1278. doi:10.1111/j.1469-7610.2005.01433.x

Murray, J., \& Farrington, D. P. (2008a). The effects of parental imprisonment on children. Crime and Justice, 37(1), 133-206. https://doi.org/10.1086/520070

Murray J., \& Farrington, D. P. (2008b). Parental imprisonment: Long-lasting effects on boys' internalizing problems through the life course. Development and Psychopathology, 20(1), 273-290. https://doi.org/10.1017/S0954579408000138

Nelson, M., Deess, P., \& Allen, C. (1999). The first month out: Post incarceration experiences in New York City. New York: Vera Institute of Justice. Retrieved from http://fsr.ucpress.edu/content/24/1/72

Padgett, D. K. (2008). Qualitative methods in social work research. Thousand Oaks, CA: Sage.

Parke, R. D., \& Clarke-Stewart, K. A. (2003). The effects of parental incarceration on children: Perspectives, promises, and policies. In J. Travis \& M. Waul (Eds.), Prisoners once removed (pp. 189-232). Washington, DC: Urban Institute Press.

Phillips, S. D., Erklani, A., Keeler, G. P., Costello, E. J., \& Angold, A. (2006). Disentangling the risks: Parent criminal justice involvement and children's exposure to family risks. Criminology and Public Policy, 5(4), 677-702. doi:10.1111/j.1745-9133.2006.00404.x

Rose, D. R., \& Clear, T. R. (2003). Incarceration, reentry, and social capital: Social networks in the balance. In J. Travis \& M. Waul (Eds.), Prisoners once removed (pp. 313-341). Washington, DC: Urban Institute.

Sampson, R. J., \& Loeffler, C. (2010). Punishment's place: The local concentration of mass incarceration. Daedalus, 139(3), 20-31. doi:10.1162/DAED_a_00020 
Sroufe, L. A. (1998). The role of infant-caregiver attachment in development. In J. Belsky and T. Nezworski (Eds.), Clinical implications of attachment (pp. 18-38). Hillsdale, NJ: Erlbaum.

Tasca, M., Rodriguez, N., \& Zatz, M. S. (2011). Family and residential instability in the context of paternal and maternal incarceration. Criminal Justice and Behavior, 38(3), 231-247. doi: $10.1177 / 0093854810391632$

Travis, J., \& Waul, W. (2003). Prisoners once removed: The children and families of prisoners. In J. Travis \& M. Waul (Eds.), Prisoners once removed (pp. 1-29). Washington, DC: Urban Institute.

Tutty, L. M., Rothery, M. A., \& Grinnell, R. M. Jr. (1996). Qualitative research for social workers: Phases, steps, \& tasks. Boston: Allyn and Bacon.

Western, B., \& Petit, B. (2010). Collateral cost: Incarceration's effect on economic mobility. Washington, DC: The Pew Charitable Trusts.

Wildeman, C. (2010). Paternal incarceration and children's physical aggressive behaviors: Evidence from the Fragile Families and Child Wellbeing Study. Social Forces, 89(1), 285-309. doi:10.1353/sof.2010.0055

Wildeman, C., (2014). Parental incarceration, child homelessness, and the invisible consequences of mass imprisonment. Annals of the American Academy of Political and Social Sciences, 651(1), 74-96. doi:10.1177/0002716213502921

Wildeman, C., \& Wakefield, S. (2014). The long arm of the law: The concentration of incarceration in families in the era of mass incarceration. Journal of Gender, Race and Justice, 17(2), 367-389. 
Zahn-Waxler, C., Klimes-Dougan, B., \& Slattery, M. J. (2000). Internalizing problems of childhood and adolescence: Prospects, pitfalls, and progress in understanding the development of anxiety and depression. Development and Psychopathology, 12(3), 433466. 